\title{
Long-term Outcome of Deep Brain Stimulation in Intralaminar Thalamus for Refractory Tourette Syndrome: A Case Report
}

\author{
Made Agus Mahendra Inggas ${ }^{1 *}$ (D), Dewa Ayu Ina Dianata ${ }^{2}$ D, Rocksy F. V. Situmeang ${ }^{3}$, Eka J. Wahjoepramono ${ }^{1}$, Takanobu Kaido \\ ${ }^{1}$ Department of Neurosurgery, Faculty of Medicine, Universitas Pelita Harapan, Tangerang, Indonesia; ${ }^{2}$ Department of General \\ Medicine, Faculty of Medicine, Brawijaya University, Malang, Indonesia; ${ }^{3}$ Department of Neurology, Faculty of Medicine, \\ Universitas Pelita Harapan, Tangerang, Indonesia; ${ }^{4}$ Department of Health and Nutrition, Osaka Shoin Women's University, \\ Higashiosaka, Japan
}

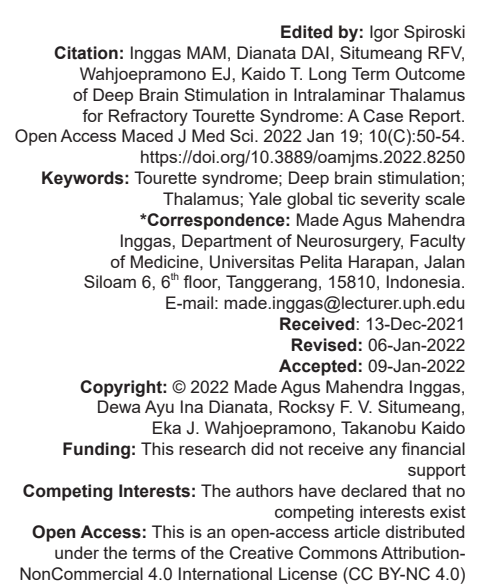

\begin{abstract}
BACKGROUND: Tourette syndrome (TS) is a neurobehavioral disease that has onset at an early age around 5-7 years old. This disease affects $0.3-0.8 \%$ of young age population. With criteria diagnosis at least one vocal and two motor tics beginning before 18 years old. The symptoms of tics remain unusual from a social point of view thus making it difficult for patients to evolve their professional life and education level. We present a case report of a young male patient with refractory TS with a Yale Global Tic Severity Scale (YGTSS) score of 88 out of 100; he has experienced remarkable improvement after undergoing a deep brain stimulation (DBS) procedure.
\end{abstract}

CASE REPORT: A 23-year-old male came to our neurosurgery outpatient clinic who had had a history of TS since 8 years ago. He had facial and jumping-type tics. Lately, his jumping movements cannot be controlled, with increasing frequency and intensity. The maximum tic-free interval is only $30 \mathrm{~min}$. On 1st-time evaluation in the neurosurgery outpatient clinic, he scored 88 out of 100 on the YGTSS even after medication treatment, repetitive transcrania magnetic stimulation, and behavioral therapies. The DBS procedure was carried out in November 2018 with targets on the bilateral intralaminar nuclei of thalamus (centromedian nucleus). The result is convincing, with decrease of YGTSS score until 14 after 3 years evaluation postsurgery.

CONCLUSION: After performing DBS targeting the bilateral thalamus (central thalamus nucleus), the severity of tic was dramatically reduced. The result is pleasing to the patient as they can resume activity in public and return to college. Case reports regarding the treatment of refractory TS with DBS are still rare in Indonesia. To the best of our knowledge, this is the first such report with long-term follow-up in South East Asia.

\section{Introduction}

Tourette syndrome (TS) is a neurobehavioral disease that has onset at an early age around $5-7$ years old. This disease affected $0.3-0.8 \%$ young age population [1], [2]. With criteria diagnosis at least one vocal and two motor tics beginning before 18 years old. Tics define as sounds or movements that produce semi-involuntary with short and sudden duration. People who experience tics can suppress the urge of the tic but not entirely. The reason TS is categorized as neurobehavioral disease is in some cases; it can be accompanied by obsessive-compulsive disorder, impulse control, attention deficit hyperactivity syndrome, and autism spectrum disorders [3], [4], [5], [6]. The majority of TS patients will have a good symptomatic prognosis where the symptoms will decrease and even disappear at the age of 15-17 years. Although tics in TS does not affect cognition and the intellect, the symptoms of tic remain unusual from a social point of view; thus making it difficult for patients to evolve their professional life and education level [7]. The pathophysiology is associated with impaired inhibition of the striatalthalamic-cortical (mesolimbic) pathway [3].

Treatment modalities for TS include medications, alone or in combination with behavioral therapy. Other options, such as deep brain stimulation (DBS), are usually recommended for patients who are no longer responsive to conventional treatments or those who develop disabling refractory symptoms [8]. DBS constitute an invasive neuromodulation technique involving the placement of electrodes that provide stimulation to subcortical and cortical structures. The goals of this technique are to improve function and mediate changes in brain tissue affected with neuron disease [9]. Clinical evidence supports the effectiveness of DBS in treating symptoms of movement disorder such as tremor, tardive dyskinesia, and chorea [10], [11], [12] . Target selection for DBS is associated with the dysfunctional striato-pallido-thalamo-cortical network. Modulation of the structures included in this network is believed to reduce the symptoms of TS [13], [14], [15]. The structures most frequently used as DBS targets 
include the thalamic nuclei and the globus pallidus segment [16].

The Yale Global Tic Severity Scale (YGTSS) is reliable, valid, and is considered to be the gold standard instrument for tic assessment in patients with TS and other tic-related disorders [17]. Reports of a decrease in the YGTSS score following therapy indicates successful tic control [18]. We report the case of a young male with refractory TS, refractory toward multiple medications, who underwent DBS with successful amelioration of tics. To the best of our knowledge, this is the first of such a report in Indonesia.

\section{Case Report}

\section{Characteristics of the patient}

A 23-year-old right-handed male presented to the neurosurgery outpatient clinic with a diagnosis of TS 8 years prior. He first experienced involuntary eye-blinking, followed by jerk-like movements of the shoulder, and twitching of the nose and mouth. Symptoms gradually worsened with time before he received clonidine $(3 \times 150 \mu \mathrm{g})$ and haloperidol $(3 \times 5 \mathrm{mg})$ at 15 years of age, after which the symptoms were well-controlled for a period of 3 years. At the age of 18 the patient attended university, and complained that the symptoms were no longer responding to those drugs. The symptoms developed into utterances of throat clearing, coughing, sniffing, roaring (animal sounds), and other simple phonic tics (syllables, words, echolalia, palilalia). Motor tics symptoms included facial twitching such as touching the shoulders with the chin or lifting the chin up, throwing the head back as if to get hair out of the eyes; arm and hand movements such as quickly flexing the arms and extending them, nail-biting, poking with fingers and popping knuckles, passing hand through the hair in a combing-like fashion, writing tics, and pulling back on the pencil while writing; and hand and foot movements such as kicking, skipping, and knee bending, flexing and extension of the ankles, shaking, and stomping and tapping the foot. There are also other complex motions such as copying the actions of others (echopraxia). Several drugs were attempted, such as risperidone, alprazolam, amitriptyline, clonazepam, topiramate, and tizanidine, to no significant result. The symptoms, particularly motor tic, worsened. The jumping movements could not be controlled, with increasing frequency and intensity. The maximum ticfree interval was only $30 \mathrm{~min}$. The jump became higher, with the time of attack being unpredictable. It can appear when standing, sitting, or lying down. The presence of stress and depression will exacerbate his complaints. The patient has also received repetitive transcranial magnetic stimulation and behavioral therapies, without improvement. The tics became increasingly apparent and interfered with social activities, necessitating the patient to drop out of college and remain house-bound for over a year. On physical examination, the patient was found to be slightly hypertensive $(130-150 / 80 \mathrm{mmHg})$ and obese (body mass index $30.3 \mathrm{~kg} / \mathrm{m}^{2}$ ), other vital signs were within normal limits. The general and neurological examination found no abnormalities. On the YGTSS, the patient scored 88 (motor 25 , phonic 13 , impairment 50) out of 100 (Table 1). On the Hamilton

Table 1: The YGTSS scores of the patient, with corresponding drugs and DBS settings

\begin{tabular}{|c|c|c|c|c|c|c|c|}
\hline \multirow{2}{*}{$\begin{array}{l}\text { Date (day/month/year) } \\
\text { Post-operative months }\end{array}$} & \multirow{2}{*}{$\begin{array}{l}\text { Pre-operative } \\
21 \text { November } 18\end{array}$} & \multicolumn{6}{|l|}{ Post-operative } \\
\hline & & $\begin{array}{l}19 \text { December } 18 \\
1\end{array}$ & $\begin{array}{l}15 \text { April } 19 \\
5\end{array}$ & $\begin{array}{l}11 \text { June } 19 \\
6\end{array}$ & $\begin{array}{l}01 \text { March } 21 \\
27\end{array}$ & $\begin{array}{l}24 \text { June } 21 \\
31\end{array}$ & $\begin{array}{l}22 \text { September } 21 \\
34\end{array}$ \\
\hline \multicolumn{8}{|l|}{ Number } \\
\hline Motor & 5 & 2 & 2 & 2 & 1 & 4 & 1 \\
\hline Phonic & 4 & 1 & 0 & 0 & 0 & 0 & 0 \\
\hline \multicolumn{8}{|l|}{ Frequency } \\
\hline Motor & 5 & 3 & 2 & 2 & 1 & 1 & 1 \\
\hline \multicolumn{8}{|l|}{ Intensity } \\
\hline Motor & 5 & 2 & 2 & 2 & 1 & 3 & 1 \\
\hline Phonic & 3 & 1 & 0 & 0 & 0 & 0 & 0 \\
\hline \multicolumn{8}{|l|}{ Complexity } \\
\hline Motor & 5 & 2 & 2 & 2 & 0 & 3 & 1 \\
\hline Phonic & 2 & 0 & 0 & 0 & 0 & 0 & 0 \\
\hline \multicolumn{8}{|l|}{ Interference } \\
\hline Motor & 5 & 1 & 1 & 1 & 0 & 0 & 0 \\
\hline Phonic & 2 & 0 & 0 & 0 & 0 & 0 & 0 \\
\hline Impairment & 50 & 10 & 10 & 10 & 10 & 10 & 10 \\
\hline \multicolumn{8}{|l|}{ Scoring } \\
\hline Motor Tic Severity & 25 & 10 & 9 & 9 & 3 & 11 & 4 \\
\hline Vocal Tic Severity & 13 & 3 & 0 & 0 & 0 & 0 & 0 \\
\hline \multicolumn{8}{|l|}{ Total Tic Severity Score } \\
\hline $\begin{array}{l}\text { Motor + Vocal Tic } \\
\text { Severity }\end{array}$ & 38 & 13 & 9 & 9 & 3 & 11 & 4 \\
\hline \multicolumn{8}{|l|}{ Total Yale Global Tic } \\
\hline \multicolumn{8}{|l|}{ Severity Scale Score } \\
\hline $\begin{array}{l}\text { Total TIC Severity Score } \\
+ \text { Impairment }\end{array}$ & 88 & 23 & 19 & 19 & 13 & 21 & 14 \\
\hline Drugs & $\begin{array}{l}\text { Haloperidol } 1-1-1 \mathrm{mg} \\
\text { Clonidine } 2 \times 75 \mu \mathrm{g}\end{array}$ & $\begin{array}{l}\text { Haloperidol } 1.5-1.5- \\
1.5 \mathrm{mg} \\
\text { Clonidine } 2 \times 75 \mu \mathrm{g}\end{array}$ & $\begin{array}{l}\text { Haloperidol } 3-3-3 \mathrm{mg} \\
\text { Clonidine } 2 \times 75 \mu \mathrm{g}\end{array}$ & $\begin{array}{l}\text { Haloperidol } 5-5-3 \mathrm{mg} \\
\text { Clonidine } 2 \times 75 \mu \mathrm{g}\end{array}$ & $\begin{array}{l}\text { Haloperidol } 5-3-3 \mathrm{mg} \\
\text { Clonidine } 2 \times 75 \mu \mathrm{g}\end{array}$ & $\begin{array}{l}\text { Haloperidol 5-3-3 mg } \\
\text { Clonidine } 2 \times 75 \mu \mathrm{g}\end{array}$ & $\begin{array}{l}\text { Haloperidol } 5-3-3 \mathrm{mg} \\
\text { Clonidine } 1 \times 75 \mu \mathrm{g}\end{array}$ \\
\hline DBS Setting & & & $\begin{array}{l}4.0 \mathrm{v} / 60 \mu \mathrm{s} / 130 \mathrm{~Hz} \\
\text { (09 July 2019) }\end{array}$ & $\begin{array}{l}4.5 \mathrm{v} / 60 \mu \mathrm{s} / 130 \mathrm{~Hz} \\
(01 \text { November } 2019 \text { ) }\end{array}$ & $\begin{array}{l}4.8 \mathrm{v} / 60 \mu \mathrm{s} / 130 \mathrm{~Hz} \\
\text { (07 July 2021) }\end{array}$ & $\begin{array}{l}5.0 \mathrm{v} / 60 \mu \mathrm{s} / 130 \mathrm{~Hz} \\
(21 \text { July 2021) }\end{array}$ & \\
\hline
\end{tabular}




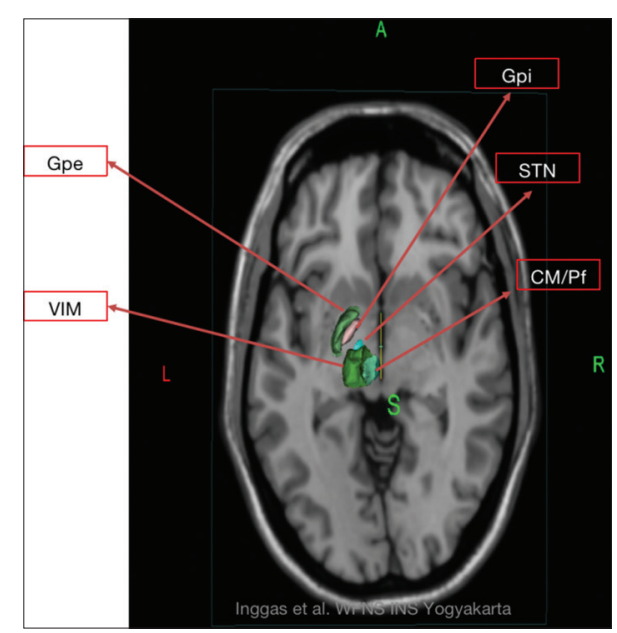

Figure 1: The deep brain stimulation target structures. The target location was bilateral thalamus (centromedian nucleus). Near the anterior commissure - posterior commissure line line Under the globus pallidus internal and external segments

Depression Rating Scale, the patient scored 13 (mild depression). A cognitive evaluation was found to be normal.

\section{DBS}

After an extensive discussion regarding the potential benefits of DBS, its risks, and complications, he was scheduled for surgery under general anesthesia. The DBS procedure was carried out in November 2018 with targets on the bilateral intralaminar nuclei of thalamus (centromedian nucleus). The target was defined as $6.5 \mathrm{~mm}$ lateral to the midline, $4.0 \mathrm{~mm}$ posterior to the midcommissural point, and $1.5 \mathrm{~mm}$ superior to the anterior commissure-posterior commissure plane as projected in Figure 1. We generated this target area in accordance with the procedure performed by Kaido et al. in a previous study [19]. Microstimulation was performed with the patient awake after the electrode was implanted at the target. The patient showed tics improvement without any side effects when the stimulus parameter was $2.5 \mathrm{~V}$ of voltage, $130 \mathrm{~Hz}$ of frequency, and $90 \mathrm{~ms}$ of pulse width with the pulse generators (Kinetra, Medtronic, Minneapolis, MN, USA).

\section{Post-operative outcome}

One month post operation, the patient came back to the neurosurgery outpatient clinic. The patient's YGTSS score showed a significant decrease to 23 (motor 10, phonic 3, impairment 10). On the second visit, around 2 months post-operative that the YGTSS score decreased to 19 ((motor 9, phonic 0 , impairment 10) 2 month and persisted on the third visit. During the 6 months evaluation period after the DBS procedure, no side effect was found in the patient. After the DBS procedure, there was a remarkable improvement in symptom severity and quality of life. Routine evaluations are continuously held to adjust drug dosing and DBS settings, along with nutritional and psychological support. The patient followed a long-term follow-up program that the neurosurgery department and neurology department monitored. After 3 years post-operation, his symptoms are getting better, with YGTSS Improving to 14 (motor 4, phonic 0, impairment 10).

\section{Discussion}

The diagnosis of TS is made with the presence of at least one vocal and two motor tics with an onset before 18 years of age and duration lasting more than a year, given other possible causes have been excluded. TS may also be accompanied by behavioral disturbances [20]. Tics are sudden, intermittent, involuntary, or semi-voluntary movements (motor tics) or sounds (phonic/vocal tics). The YGTSS is used as an instrument to assess tic severity, in which a score exceeding 35 denote severe symptoms. Medication resistance is determined as the absence of symptomatic improvement after use of three agents, including typical and atypical neuroleptic drugs [21]. The patient demonstrated uncontrollable jumping movements with increasing frequency and intensity, and vocal tics such as yawning and slight coughing. He scored 88 of 100 on the YGTSS. The patient has undergone pharmacological treatment, repetitive transcranial magnetic stimulation, and behavioral therapy, without symptomatic improvement. Based on the severity, the patient has severe refractory TS. Surgical treatment options such as DBS are recommended in patients who are no longer responsive to conventional pharmacological treatments or those who develop disabling refractory symptoms [8].

The DBS procedure targets structures associated with the striatum-pallido-thalamocortical network [13], [14], [15]. In this patient, the target is located in the bilateral thalamus (centromedian nucleus). Recent studies focusing on the thalamus as a DBS target have highlighted the thalamus as a strategic location of motor function in the cerebral cortex and motor-related subcortical structures, particularly the basal ganglia and cerebellum. A retrospective study that used YGTSS scoring as an evaluation instrument in TS patients demonstrated that DBS in centromedianparafascicular (CM-Pf) complex provides $46 \%$ improvement in motor tics and $52 \%$ improvement in phonic tics [22], [23]. After DBS, the patient showed substantial improvement, down to a score of 19 on the YGTSS, on the third post-procedure evaluation, corresponding to a $78 \%$ decrease in severity. This improvement is supported by a study that showed an average of $50 \%$ improvement in overall tic severity (total YGTSS score) after DBS in the medial thalamus, and 
this improvement can be achieved in a 6-month postprocedure [24]. The latest evaluation on this patient is 3 years after surgery. His symptoms are getting better, with a YGTSS score of 14.

Different studies have revealed varying side effects of DBS on the thalami. There have been reports of transient blurring of vision, dysarthria, recurrent tension headache, and a single seizure-like episode occurring after DBS in the CM-pf region [23], [25]. In contrast, other studies have not revealed any side effects following the procedure [21]. Data from the DBS Registry and Database from the TAA have suggested that many regions can be targets of DBS [26]. As of the present, there are yet any guidelines elucidating which target is the most effective, hence further studies are needed to determine the best DBS target in providing maximal symptom relief and minimal adverse effects in cases of TS.

\section{Conclusion}

After performing DBS targeting the bilateral thalamus (central thalamus nucleus), the severity of TIC was reduced. The result is pleasing to the patient as they can resume activity in public and return to college. Case reports regarding the treatment of refractory TS with DBS are still rare in Indonesia. To the best of our knowledge, this is the first such report with long-term follow-up in South East Asia. Many studies have been done in effort to determine appropriate targets for DBS. This case report can support the evidence that bilateral thalamic DBS is a promising target based on its safety and effectiveness in the treatment of TS.

\section{Authors' Contributions}

All authors participated in the process of the manuscript's writing and approved the final version

\section{Acknowledgments}

The abstract was presented at The $23^{\text {rd }}$ Annual Scientific Meeting of Indonesian Society of Neurological Surgeon in conjunction with The WFNS Educational Course. 2019. Yogyakarta, Indonesia.

\section{Ethics statement}

The patients/participants provided their written informed consent to participate in this study. Written informed consent was obtained from the individual for the publication of any potentially identifiable images or data included in this article.

\section{References}

1. Scharf JM, Miller LL, Mathews CA, Ben-Shlomo Y. Prevalence of Tourette syndrome and chronic tics in the population-based Avon longitudinal study of parents and children cohort. J Am Acad Child Adolesc Psychiatry. 2012;51(2):192-201. https://doi. org/10.1016/j.jaac.2011.11.004 PMid:22265365

2. Porta M, Servello D, Sevello D, Sassi M, Brambilla A, Defendi S et al. Issues related to deep brain stimulation for treatmentrefractory Tourette's syndrome. Eur Neurol. 2009;62:264-73.

3. Jankovic J. Tourette's syndrome. $N$ Engl J Med. 2001;345(16):1184-92. https://doi.org/10.1056/NEJMra010032 PMid: 11642235

4. Eapen V, Cavanna AE, Robertson MM. Comorbidities, socia impact, and quality of life in Tourette syndrome. Front Psychiatry. 2016;7:97. https://doi.org/10.3389/fpsyt.2016.00097 PMid:27375503

5. American Psychiatric Association. Diagnostic and Statistica Manual of Mental Disorders: DSM-5. $5^{\text {th }}$ ed. Washington, DC: American Psychiatric Association; 2013.

6. LeckmanJF. Tourette'ssyndrome.Lancet.2002;360(9345):1577-86 https://doi.org/10.1016/S0140-6736(02)11526-1 PMid:12443611

7. Eddy CM, Rickards HE, Cavanna AE. Treatment strategies for tics in Tourette syndrome. Ther Adv Neurol Disord. 2011;4(1):25-45. https://doi.org/10.1177/17562856103902618 PMid:21339906

8. Cavanna AE, Eddy CM, Mitchell, R, Pall, H, Mitchell, I, Zrinzo, L, et al. An approach to deep brain stimulation for severe treatment-refractory Tourette syndrome: The UK perspective. $\mathrm{Br}$ J Neurosurg. 2011;25(1):38-44. https://doi.org/10.3109/026886 97.2010 .534200 PMid:21158507

9. Herrington TM, Cheng JJ, Eskandar EN. Mechanisms of deep brain stimulation. J Neurophysiol. 2016;115(1):19-38. https:// doi.org/10.1152/jn.00281.2015 PMid:26510756

10. Deng ZD, Li DY, Zhang CC, Pan YX, Zhang J, Jin H, et al. Longterm follow-up of bilateral subthalamic deep brain stimulation for refractory tardive dystonia. Parkinsonism Relat Disord. 2017;41:58-65. https://doi.org/10.1016/j.parkreldis.2017.05.010 PMid:28552340

11. Gonzalez V, Cif L, Biolsi B, Garcia-Ptacek S, Seychelles A Sanrey E, et al. Deep brain stimulation for Huntington's disease: Long-term results of a prospective open-label study. J Neurosurg. 2014;121(1):114-22. https://doi.org/10.3171/2014.2.JNS131722 PMid:24702329

12. Barbey A, Bloch J, Vingerhoets FJ. DBS in dystonia and other hyperkinetic movement disorders. Curr Treat Options Neurol. 
2015;17(9):373. https://doi.org/10.1007/s11940-015-0373-2 PMid:26257150

13. Worbe $\mathrm{Y}$, Marrakchi-Kacem L, Lecomte $\mathrm{S}$, Valabregue $\mathrm{R}$, Poupon F, Guevara P, et al. Altered structural connectivity of cortico-striato-pallido-thalamic networks in Gilles de la Tourette syndrome. Brain. 2015;138(Pt 2):472-82.

PMid:25392196

14. Baldermann JC, Schuller T, Huys D, Becker I, Timmermann L, Jessen $F$, et al. Deep brain stimulation for Tourette-syndrome: A systematic review and meta-analysis. Brain Stimul. 2016;9(2):296-304. https://doi.org/10.1016/j.brs.2015.11.005 PMid:26827109

15. Alam M, Schwabe K, Lütjens G, Capelle HH, Manu M, von Wrangel $\mathrm{C}$, et al. Comparative characterization of single cell activity in the globus pallidus internus of patients with dystonia or Tourette syndrome. J Neural Transm. 2015;122(5):687-99. https://doi.org/10.1007/s00702-014-1277-0

PMid:25081018

16. Albin RL. Tourette syndrome: A disorder of the social decisionmaking network. Brain. 2018;141(2):332-47. https://doi. org/10.1093/brain/awx204

PMid:29053770

17. Haas M, Jakubovski E, Fremer C, Dietrich A, Hoekstra PJ, Jäger $B$, et al. Yale global tic severity scale (YGTSS): Psychometric quality of the gold standard for tic assessment based on the large-scale EMTICS study. Front Psychiatry. 2021;12:626459. https://doi.org/10.3389/fpsyt.2021.626459 PMid:33716826

18. Akbarian-Tefaghi L, Zrinzo L, Foltynie T. The use of deep brain stimulation in Tourette syndrome. Brain Sci. 2016;6(3):35. https://doi.org/10.3390/brainsci6030035

19. KaidoT,OtsukiT,KanekoY,TakahashiA,OmoriM,OkamotoT.Deep brain stimulation for Tourette syndrome: A prospective pilot study in Japan. Neuromodulation. 2011;14(2):123-8; discussion 129. https://doi.org/10.1111/j.1525-1403.2010.00324.x

PMid:21992198
20. Riederer F, Stamenkovic M, Schindler SD, Kasper S. Das tourette-syndrom eine ubersicht [Tourette's syndrome-a review]. Nervenarzt. 2002;73(9):805-19. https://doi.org/10.1007/ s00115-002-1270-y

PMid: 12215871

21. Colquhoun M, Stern J, Collicott N, Williams D, Grabecki K, Simmons H, Robertson MR. Severe refractory Tourette syndrome. J Neurol Neurosurg Psychiatry. 2014;85:e3. https:// doi.org/10.1136/jnnp-2014-308883.35

22. Cury RG, Lopez WO, Dos Santos Ghilardi MG, Barbosa DC Barbosa ER, Teixeira MJ, et al. Parallel improvement in anxiety and tics after DBS for medically intractable Tourette syndrome: A long-term follow-up. Clin Neurol Neurosurg. 2016;144:33-5. https://doi.org/10.1016/j.clineuro.2016.02.030 PMid:26963088

23. Testini $P$, Zhao $C Z$, Stead $M$, Duffy PS, Klassen BT, Lee $\mathrm{KH}$. Centromedian Parafascicular complex deep brain stimulation for Tourette syndrome: A retrospective study. Mayo Clin Proc. 2016;91(2):218-25. https://doi.org/10.1016/j. mayocp.2015.11.016

PMid:26848003

24. Dowd RS, Pourfar M, Mogilner AY. Deep brain stimulation for Tourette syndrome: A single-center series. J Neurosurg. 2018;128(2):596-604. https://doi.org/10.3171/2016.10.JNS161573 PMid:28387621

25. Marano M, Migliore S, Squitieri F, Insola A, Scarnati E, Mazzone P. CM-Pf deep brain stimulation and the long term management of motor and psychiatric symptoms in a case of Tourette syndrome. J Clin Neurosci. 2019;62:269-72. https://doi. org/10.1016/j.jocn.2018.12.029

PMid:30612913

26. Akbarian-Tefaghi L, Akram $H$, Johansson J, Zrinzo L, Kefalopoulou Z, Limousin P, et al. Refining the deep brain stimulation target within the limbic globus pallidus internus for Tourette syndrome. Stereotact Funct Neurosurg. 2017;95(4):251-8. https://doi.org/10.1159/000478273 PMid:28787721 